Article

\title{
Simulation of AlGaN/GaN HEMTs' Breakdown Voltage Enhancement Using Gate Field-Plate, Source Field-Plate and Drain Field Plate
}

\author{
Biyan Liao ${ }^{1}$, Quanbin Zhou ${ }^{1}\left(\mathbb{D}\right.$, Jian Qin $^{1,2}$ and Hong Wang ${ }^{1,3, * \mathbb{C}}$ \\ 1 Engineering Research Center for Optoelectronics of Guangdong Province, School of Electronics and \\ Information Engineering, South China University of Technology, Guangzhou 510641, China; \\ lydialiao1018@163.com (B.L.); zhouquanbin86@163.com (Q.Z.); gzu_jian@gzhu.edu.cn (J.Q.) \\ 2 Department of Electronics and Communication Engineering, Guangzhou University, \\ Guangzhou 510641, China \\ 3 Zhongshan Institute of Modern Industrial Technology, South China University of Technology, \\ Zhongshan 528437, China \\ * Correspondence: phhwang@scut.edu.cn; Tel.:+86-136-0006-6193
}

Received: 9 March 2019; Accepted: 4 April 2019; Published: 7 April 2019

\begin{abstract}
A 2-D simulation of off-state breakdown voltage $\left(\mathrm{V}_{\mathrm{BD}}\right)$ for AlGaN/GaN high electron mobility transistors (HEMTs) with multi field-plates (FPs) is presented in this paper. The effect of geometrical variables of FP and insulator layer on electric field distribution and $\mathrm{V}_{\mathrm{BD}}$ are investigated systematically. The FPs can modulate the potential lines and distribution of an electric field, and the insulator layer would influence the modulation effect of FPs. In addition, we designed a structure of HEMT which simultaneously contains gate FP, source FP and drain FP. It is found that the $V_{B D}$ of AlGaN/GaN HEMTs can be improved greatly with the corporation of gate FP, source FP and drain FP. We achieved the highest $\mathrm{V}_{\mathrm{BD}}$ in the HEMT contained with three FPs by optimizing the structural parameters including length of FPs, thickness of FPs, and insulator layer. For HEMT with three FPs, FP-S alleviates the concentration of the electric field more effectively. When the length of the source FP is $24 \mu \mathrm{m}$ and the insulator thickness between the FP-S and the AlGaN surface is $1950 \mathrm{~nm}$, corresponding to the average electric field of about $3 \mathrm{MV} / \mathrm{cm}$ at the channel, $\mathrm{V}_{\mathrm{BD}}$ reaches 2200 V. More importantly, the 2D simulation model is based on a real HMET device and will provide guidance for the design of a practical device.
\end{abstract}

Keywords: AlGaN/GaN HEMTs; field-plates; off-state breakdown voltage; electric field distribution

\section{Introduction}

Gallium nitride (GaN)-based high electron mobility transistor (HEMT) has become an attractive candidate for high power applications, due to integrating lots of outstanding physical properties like high breakdown voltage, high frequency application and low on-resistance [1-3]. For power devices, the property of high breakdown voltage is particularly significant. On account of the limit of technique process, the off-state breakdown voltage $\left(\mathrm{V}_{\mathrm{BD}}\right)$ of $\mathrm{AlGaN} / \mathrm{GaN}$ HEMTs is still far from the limitation of GaN material [4].

Field-plate (FP) technology is expected to be a feasible and effective way to increase the breakdown voltage by reducing the peak value of an electric field along the channel [5]. From the perspective of field-plate position, FPs can be divided into gate field-plate (FP-G), source field plate (FP-S), and drain field plate (FP-D). Zhang, N.Q. et al. first proposed the FP-G and achieved a high $\mathrm{V}_{\mathrm{BD}}$ of $570 \mathrm{~V}$, but resulting in severe degradation of frequency characteristics [6]. Since then, multiple grating FP-G $[7,8]$ and novel FP-G structures $[9,10]$ have been invented to reduce the frequency 
degradation. Relevant analytical models [11,12] and reliability improvement [13] were also reported, providing a deeper insight into the relationship between FPs and $V_{B D}$. In terms of FP-S, a T-shaped FP-S was designed by Mao Wei et al. and it attained high $\mathrm{V}_{\mathrm{BD}}$ and high efficiency remarkably [14]. In order to enhance $V_{\mathrm{BD}}$ more effectively, the combination of both FP-G and FP-S is inevitable [15-17]. An extremely high $V_{\mathrm{BD}}$ of $8300 \mathrm{~V}$ was achieved by using the thick poly-AlN passivation on HEMTs with both FP-G and FP-S [18]. Toshiki Kabemura et al. made a 2-D analysis of breakdown characteristics of FP HEMTs with a high- $k$ passivation layer, confirming that the $V_{B D}$ would increase with relative permittivity increasing [19]. For investigating the impact of FP-G and FP-S on the capacitances, Aamir et al. modeled the bias dependence of terminal capacitances, and the proposed model is in excellent agreement with measured data [20]. Meanwhile, the incorporation of FP-S and FP-D was considered to be an effective way to improve $\mathrm{V}_{\mathrm{BD}}$ and reduce the on-resistance to about $0.6 \mathrm{~m} \Omega \cdot \mathrm{cm}^{2}$ [21]. However, in comparison with FP-G and FP-S, FP-D is rarely induced to enhance $V_{B D}$ but mostly induced to improve reverse breakdown voltage [22]. In fact, FP-D can reduce the undesired electric field peak from the metal peak introduced by annealing [23]. It is necessary to combine the three FPs. Up to now, the properties of HEMT with FP-G, FP-S and FP-D simultaneously are seldom discussed. At the same time, considering the complexity of structure, more structural parameters such as length of FPs, thickness of FPs and insulator layer are also needed to be optimized in detail. Hence, systematic simulation is necessary and will provide the guidance for experiment.

In this paper, the effect of geometrical variables of FP and insulator layer on field distribution and $\mathrm{V}_{\mathrm{BD}}$ were investigated systematically. The electric field distribution and $\mathrm{V}_{\mathrm{BD}}$ under different FP were compared by simulation using Silvaco TCAD [24]. Moreover, the FP-G, FP-S and FP-D are employed simultaneously in an AlGaN/GaN HEMT to improve $\mathrm{V}_{\mathrm{BD}}$ effectively. The physical models are illustrated in Section 2. The parameters including length of FPs, thickness of FPs, and insulator layer of FPs were optimized for improving $\mathrm{V}_{\mathrm{BD}}$. The breakdown characteristics of HEMT with FP-G, FP-S and FP-D were simultaneously discussed.

\section{Physic Models}

The two-dimensional numerical simulations were carried out by Silvaco TCAD. The simulated model was based on the experimental structure. Figure 1 shows a not-to-scale cross-section view of the device structure analyzed in this paper. The gate length $L_{G}$ was $3 \mu \mathrm{m}$, the source-to-gate distance $\mathrm{L}_{\mathrm{SG}}$ was $9 \mu \mathrm{m}$, and the gate-to-drain distance $\mathrm{L}_{\mathrm{GD}}$ was $22 \mu \mathrm{m}$. The field-plate length $\mathrm{L}_{\mathrm{FP}-\mathrm{G}^{\prime}}$ was $2 \mu \mathrm{m}$. The insulator was assumed to be $\mathrm{SiO}_{2}$ in this simulation, which was usually used in our lab. The permittivity of $\mathrm{SiO}_{2}$ was set to 5, corresponding to the value of the experimental measurement. Likewise, $\mathrm{Si}_{3} \mathrm{~N}_{4}$ [25] and $\mathrm{Al}_{2} \mathrm{O}_{3}$ [26] could also be selected as passivation, and the kind of insulator would not change the trend of $V_{B D}$ versus FPs [19]. The thickness of insulator layer $t_{1}$ and $t_{2} ;$ length of FPs $L_{F P-G}, L_{F P-S}$ and $L_{F P-D}$; and the thickness of FPs $t_{F P-G}$ and $t_{F P-S}$ are variable in the following Section. The leakage current [27], especially from the buffer layer, may result in electron injection from the channel into the buffer layer and a large drain current [28]. Setting traps in the GaN buffer is a usual way to decrease the leakage current at pinch-off state $[19,29,30]$, but it may cause a no-convergence problem. Moreover, we aimed to present the relevance between electric field distributions and FPs clearly and exclude the punch-through from the buffer layer. Therefore, with the purpose of simplifying calculation, we set the GaN buffer layer to be $200 \mathrm{~nm}$, reducing the influence of buffer leakage current flow from source to drain [31]. Besides, the thicknesses of the $\mathrm{Al}_{0.23} \mathrm{Ga}_{0.77} \mathrm{~N}$ barrier and $\mathrm{GaN}$ channel are $25 \mathrm{~nm}$ and $10 \mathrm{~nm}$ respectively.

Detailed simulation conditions are as follows. The $1 \times 10^{13} \mathrm{~cm}^{-2}$ positive charges were placed along the $\mathrm{Al}_{0.23} \mathrm{Ga}_{0.77} \mathrm{~N} / \mathrm{GaN}$ heterojunction to create the two-dimension electron gas, and the channel mobility was set to $1500 \mathrm{~cm}^{2} / \mathrm{V} \cdot \mathrm{s}$ [32]. Also, the field-dependent mobility model and Shockley-Read-Hall (SRH) Recombination model were used. Thermal impact is common in the experiments [33,34], but we did not discuss it during the simulation. The breakdown voltage simulation in this paper was based on the Selberherr's impact ionization model. The ionization coefficients were AN $=\mathrm{AP}=2.98 \times 10^{8}$ and 
$\mathrm{BN}=\mathrm{BP}=3.44 \times 10^{7}$ [35]. Moreover, simulations about breakdown performance were all carried out with the gate biased at $-6 \mathrm{~V}$, keeping devices on the off-state. Finally, $\mathrm{V}_{\mathrm{BD}}$ was defined as the drain voltage when the peak electric field in the channel reached $3 \mathrm{MV} / \mathrm{cm}[10,14,22]$.

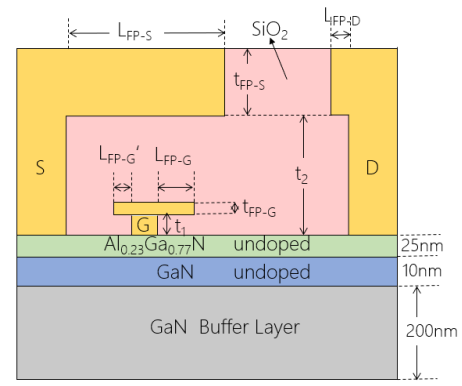

Figure 1. Schematic of HEMT with FP-G, FP-S and FP-D.

\section{Influences of Structural Parameters of Different Field-Plates}

\subsection{Gate Field-Plate}

We first discuss the influence of gate field-plate on $\mathrm{V}_{\mathrm{BD}}$. Figure 2 shows the device structure only with FP-G. Three parameters are studied, including the insulator layer thickness $t_{1}$, the FP-G length $L_{F P-G}$ and the FP-G thickness $t_{\mathrm{FP}-\mathrm{G}}$. Figure 3 a shows the distributions of electric field along the heterojunction interface for $t_{1}$ from $100 \mathrm{~nm}$ to $300 \mathrm{~nm}$ when $L_{F P-G}$ is $4 \mu \mathrm{m}$ and $t_{\mathrm{FP}-\mathrm{G}}$ is $100 \mathrm{~nm}$. For the sake of presenting the electric field peaks intuitively, we only display the electric field distributions partly around the region from gate to drain. As shown in Figure 3a, for thin insulator layer $t_{1}$ $\left(t_{1}<250 \mathrm{~nm}\right)$, the electric field at the FP-G edge is higher than the electric field at the gate edge. Due to the modulation of FP-G, the electric field at the FP-G edge reaches the breakdown standard first. Consequently, $V_{B D}$ increases with the increase of $t_{1}$. However, when $t_{1}$ further increases, the modulated effect of FP-G becomes weaker. Thus, the electric field peak shifts to the gate edge, which leads to the decrease of $\mathrm{V}_{\mathrm{BD}}$. For the structure in Figure 2, the modulate effect induced by FP-G is optimal when $\mathrm{t}_{1}=250 \mathrm{~nm}$, as shown in Figure $3 \mathrm{~b}$.

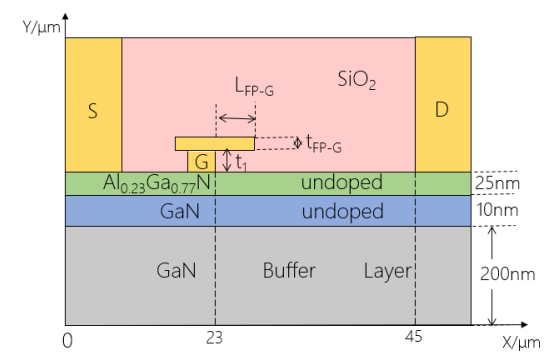

Figure 2. Device structure with FP-G analyzed in this study.

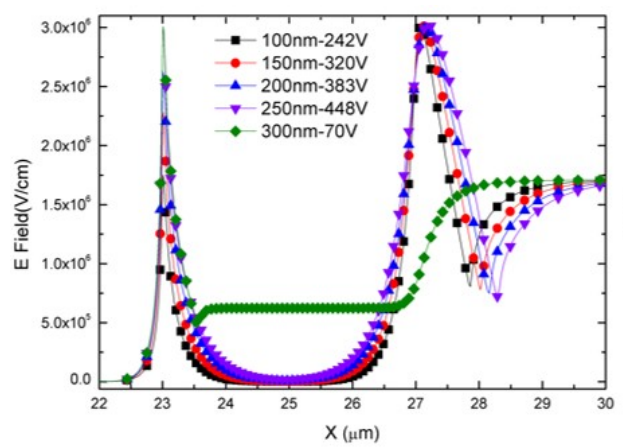

(a)

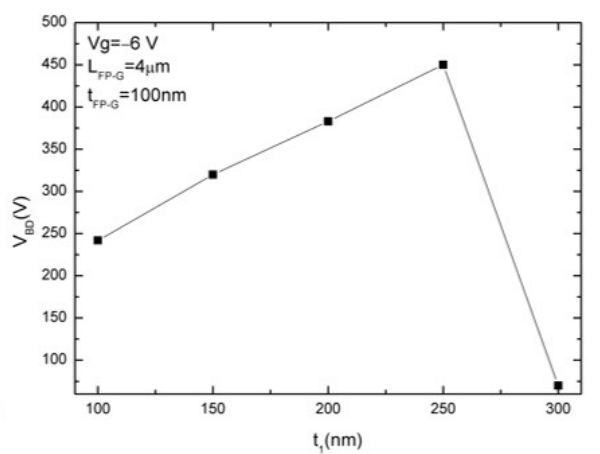

(b)

Figure 3. Cont. 


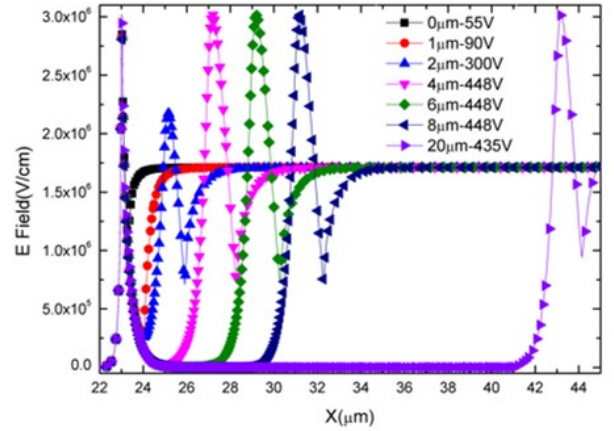

(c)

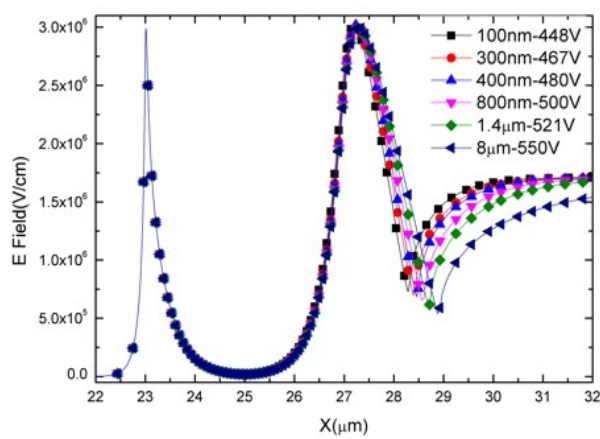

(e)

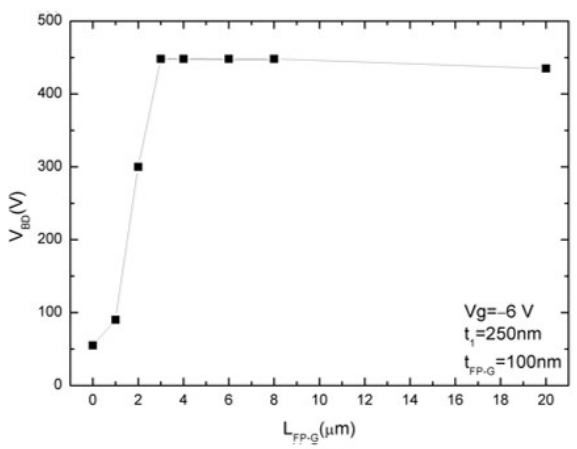

(d)

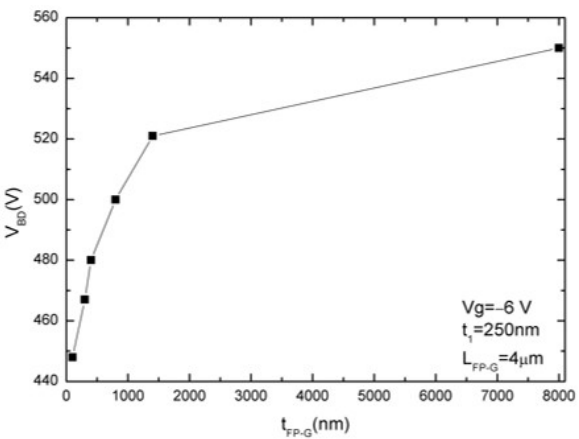

(f)

Figure 3. The electric field distributions along the channel for different values of (a) $t_{1}$, (c) $L_{F P-G}$, and (e) $t_{\mathrm{FP}-\mathrm{G}}$. The $\mathrm{V}_{\mathrm{BD}}$ for different values of $(\mathbf{b}) \mathrm{t}_{1},(\mathbf{d}) \mathrm{L}_{\mathrm{FP}-\mathrm{G}}$, and $(\mathbf{f}) \mathrm{t}_{\mathrm{FP}-\mathrm{G}}$.

Then, we change the $\mathrm{L}_{\mathrm{FP}-\mathrm{G}}$ from $0 \mu \mathrm{m}$ to $20 \mu \mathrm{m}$ and keep $\mathrm{t}_{1}$ fixed at $250 \mathrm{~nm}$. Without a field plate at the drain side, the electric field at the gate edge increases rapidly and reaches the critical breakdown field $3 \mathrm{MV} / \mathrm{cm}$ at around $V_{D}=55 \mathrm{~V}$. For short $\mathrm{L}_{\mathrm{FP}-\mathrm{G}}\left(\mathrm{L}_{\mathrm{FP}-\mathrm{G}}<4 \mu \mathrm{m}\right)$, the modulate effect of field-plate is too small to reduce the electric field peak at the gate edge, so $\mathrm{V}_{\mathrm{BD}}$ increases slowly with the increase of $\mathrm{L}_{\mathrm{FP}-\mathrm{G}}$. As shown in Figure $3 \mathrm{c}$,d, with the optimized $t_{1}$, $\mathrm{L}_{\mathrm{FP}-\mathrm{G}}$ from $4 \mu \mathrm{m}$ to $8 \mu \mathrm{m}$, all can reduce the electric field peak value along the channel effectively, and the electric field peak value of the gate edge reaches $3 \mathrm{MV} / \mathrm{cm}$ until $\mathrm{V}_{\mathrm{D}}=448 \mathrm{~V}$. When the $\mathrm{L}_{\mathrm{FP}-\mathrm{G}}$ is more than $20 \mu \mathrm{m}, \mathrm{V}_{\mathrm{BD}}$ will decrease. It is attribute to the narrower distance between the field-plate edge and the drain, which leads to the electric field at the FP-G edge reaches the critical breakdown electric field at around $V_{D}=435 \mathrm{~V}$.

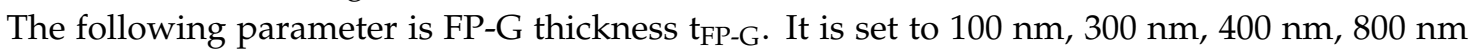
and $8 \mu \mathrm{m}$, respectively. In previous researches, there were few studies on the relationship between breakdown characteristics and the thickness of the field-plate. As shown in Figure 3e, $V_{\mathrm{BD}}$ increases with the increase of $t_{F P-G}$. This phenomenon shows that thicker FP-G can reduce the electric field at the FP-G edge. However, the improvement of $\mathrm{V}_{\mathrm{BD}}$ is not obvious even when the $\mathrm{t}_{\mathrm{FP}-\mathrm{G}}$ reaches $8 \mu \mathrm{m}$. In view of the highest $\mathrm{V}_{\mathrm{BD}}$ achievement with less changes in technology progress, we choose $\mathrm{t}_{\mathrm{FP}-\mathrm{G}}=100 \mathrm{~nm}$ as a suitable value for following researches.

\subsection{Source Field-Plate}

The FP-S is usually used in the GaN-based HEMTs in combination with the gate field-plate, with the aim of achieving a great improvement of $\mathrm{V}_{\mathrm{BD}}$. Figure 4 shows the structure with FP-S. Firstly, the relationship between FP-S and $\mathrm{V}_{\mathrm{BD}}$ is studied in the HEMT without the FP-G. The thickness of the gate was fixed at $100 \mathrm{~nm}$. From Figure 5, the effect of FP-S on $V_{B D}$ is similar to that of FP-G. With regard to $t_{2}$, the optimum value of $t_{2}$ is less than that of $t_{1}$. Because in this device, when the FP-G is fixed to $-6 \mathrm{~V}$, the FP-S is fixed to $0 \mathrm{~V}$, resulting in a higher electric field at the FP-S edge than that at the FP-G edge. Hence, to achieve the same effect of modulating the electric field by FP, the FP-S should be closer 
to the AlGaN surface. The variation trend of $\mathrm{V}_{\mathrm{BD}}$ with the length and thickness of FP-S is the same as that of FP-G. As we know, the electric field is in direct proportion to the electric potential difference, and the latter can be performed by the density of the potential line distribution. Therefore, the higher electric field corresponds to the narrower potential lines. From the potential line distributions of Figure 5g,h, we find that potential lines in (g) of FP-G edge are less crowded than that in (h) of FP-S edge even at high drain voltage, which is in accordance with electric field distributions [11]. In a word, in order to enhance $\mathrm{V}_{\mathrm{BD}}$, FP-G is more efficient than FP-S when the structure only has one FP.

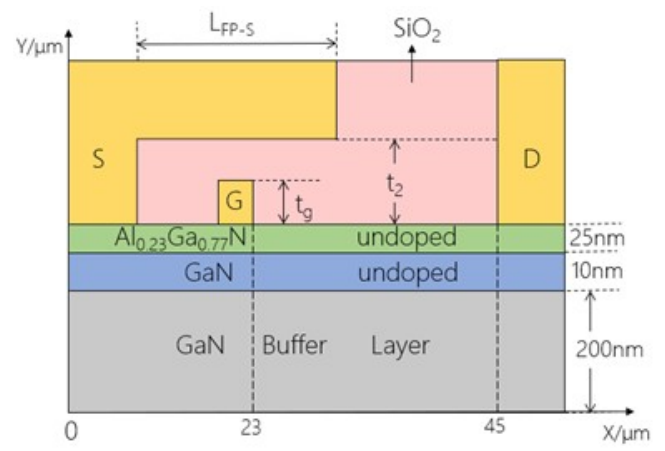

Figure 4. Device structure with FP-S analyzed in this study.

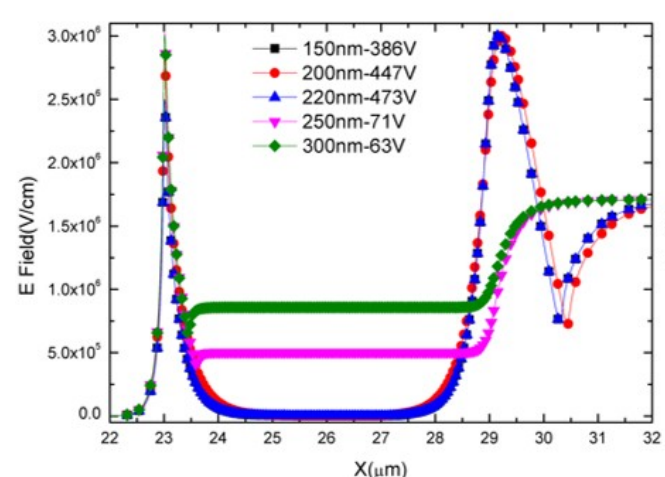

(a)

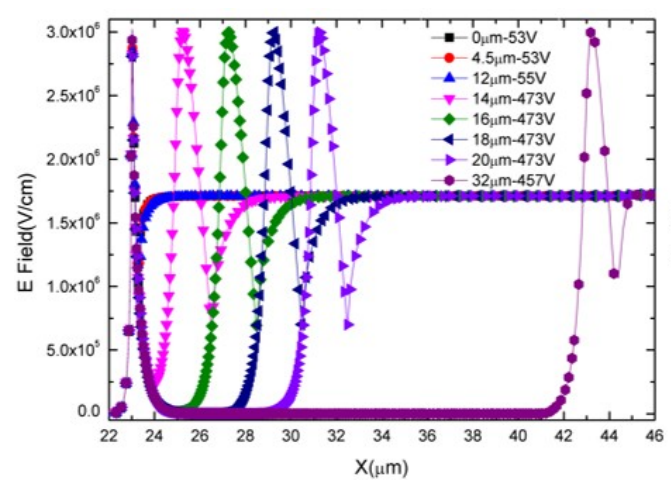

(c)

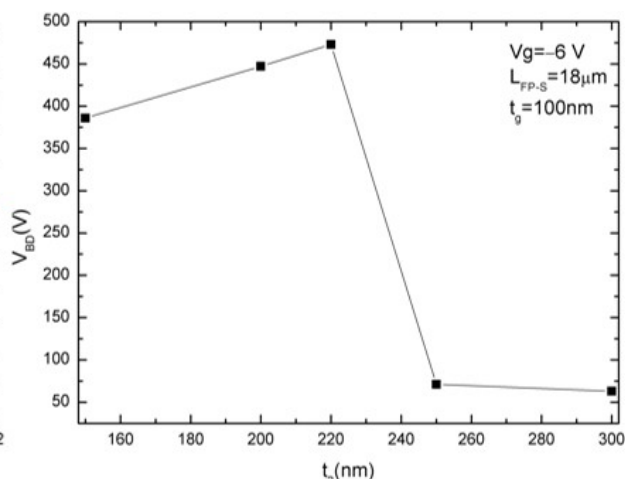

(b)

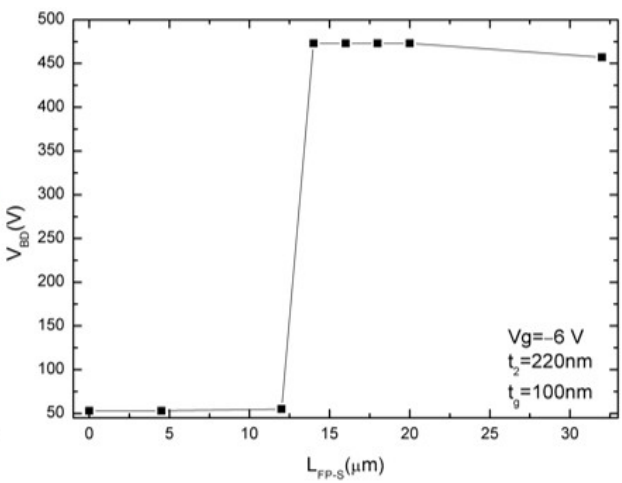

(d)

Figure 5. Cont. 


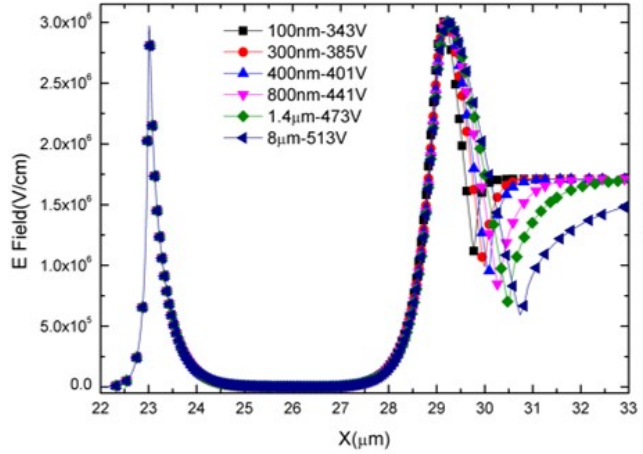

(e)

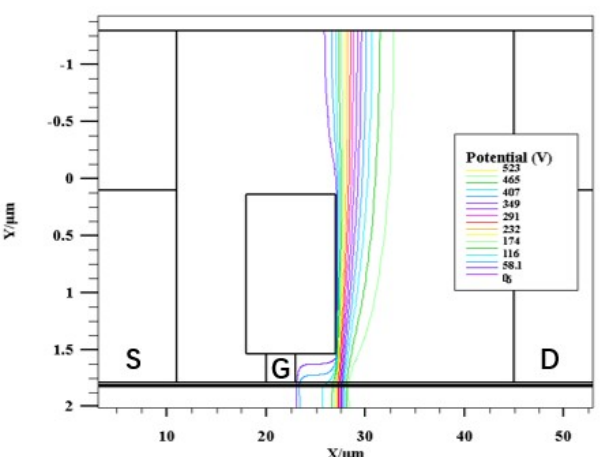

(g)

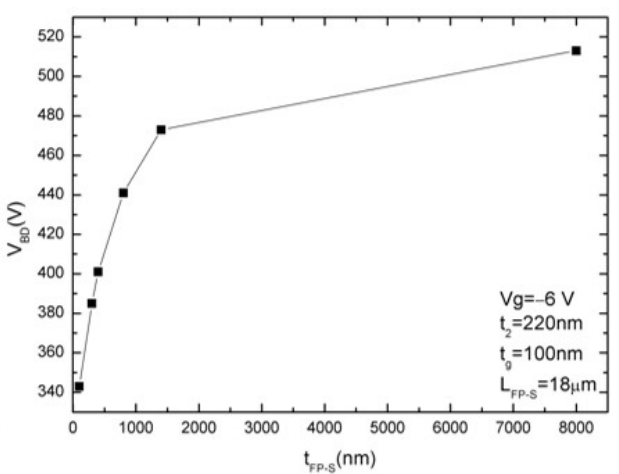

(f)

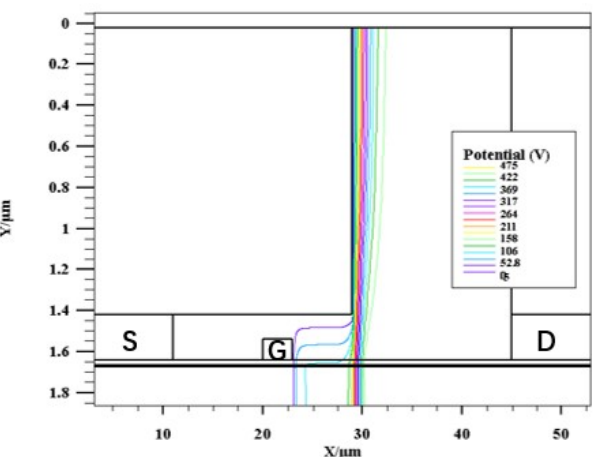

(h)

Figure 5. The electric field distributions along the channel for different values of (a) $t_{2},(c) L_{F P-S}$, and (e) $t_{F P-S}$. Off-state breakdown voltage $V_{B D}$ for different values of $(\mathbf{b}) t_{2}$, (d) $L_{F P-S}$, and (f) $t_{F P-S}$. The Potential line distributions along the channel when $(\mathrm{g}) \mathrm{t}_{1}=250 \mathrm{~nm}, \mathrm{~L}_{\mathrm{FP}-\mathrm{G}}=4 \mu \mathrm{m}, \mathrm{t}_{\mathrm{FP}-\mathrm{G}}=1.4 \mu \mathrm{m}$, $\mathrm{V}_{\mathrm{BD}}=521 \mathrm{~V}$, and (h) $\mathrm{t}_{2}=120 \mathrm{~nm}, \mathrm{~L}_{\mathrm{FP}-\mathrm{S}}=18 \mu \mathrm{m}, \mathrm{t}_{\mathrm{FP}-\mathrm{S}}=1.4 \mu \mathrm{m}, \mathrm{V}_{\mathrm{BD}}=473 \mathrm{~V}$.

\subsection{Drain Field-Plate}

For FP-D, it is usually used to improve the reverse breakdown voltage. In fact, the electric field peak from the metal peak introduced by annealing could also be reduced by FP-D. However, the electric field peak does not appear on the drain edge in the Silvaco simulation, because of the flat and smooth edge of ohmic electros. Thus, single FP-D usually has little impact on electric field distribution along the channel. However, the electric field peak at the FP-S edge will increase if the distance between FP-S and FP-D is too close. Therefore, we only explored the relationship between FP-D length and $\mathrm{V}_{\mathrm{BD}}$ when the structure has both FP-S and FP-D, as shown in Figure 6. Figure 7 shows that when $\mathrm{L}_{\mathrm{FP}-\mathrm{D}}>13 \mu \mathrm{m}, \mathrm{V}_{\mathrm{BD}}$ decreases due to the narrow distance between the two FPs. In consideration of passivation quality in the practical experiment, breakdown may occur between the two FPs. So, it may be more appropriate when $\mathrm{L}_{\mathrm{FP}-\mathrm{D}}$ is set to $1 \mu \mathrm{m}$.

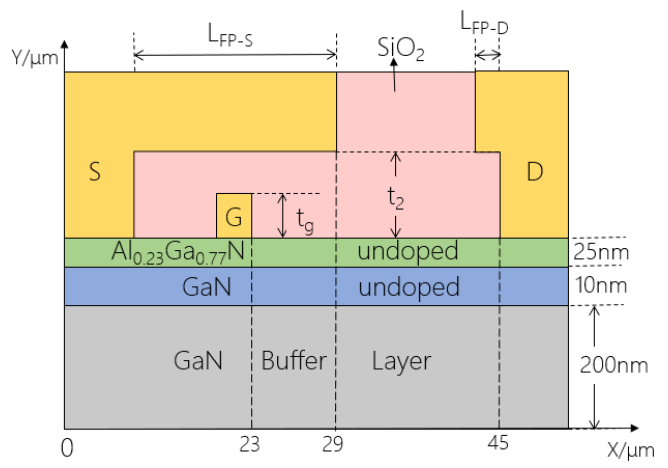

Figure 6. Device structure with FP-S and FP-D analyzed in this study. 


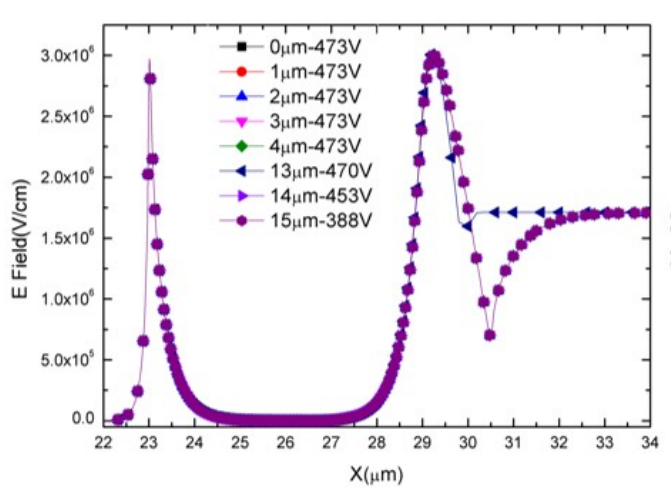

(a)

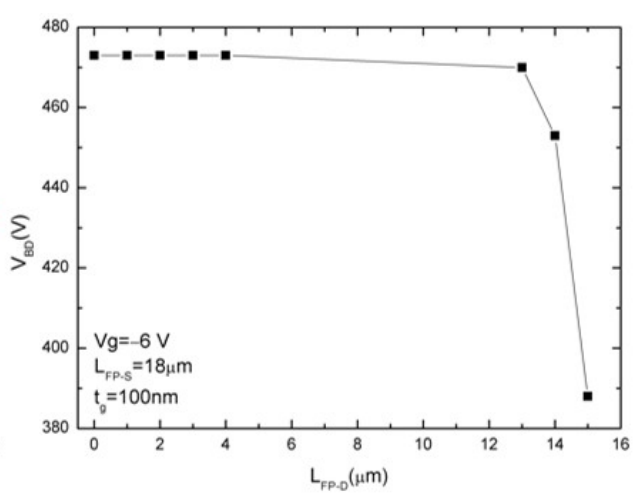

(b)

Figure 7. The electric field distributions along the channel for different values of (a) LFP-D. Off-state breakdown voltage $\mathrm{V}_{\mathrm{BD}}$ for different values of (b) $\mathrm{L}_{\mathrm{FP}-\mathrm{D}}$.

\section{Devices Contained with FP-G, FP-S, and FP-D}

For much higher $\mathrm{V}_{\mathrm{BD}}$, there is no doubt that the FP-G should be combined with the FP-S [20]. Figure 8 shows the structure of the device contained with FP-G, FP-S and FP-D simultaneously. The $\mathrm{V}_{\mathrm{BD}}$ is affected by seven variables, $t_{1}, t_{2}, L_{F P-G}, L_{F P-S}, L_{F P-D}, t_{F P-G}$, and $t_{F P-S}$. Since many parameters should be optimized, the procedure is significant. Because the electric field peak at the gate edge is mainly affected by FP-G, it can be suppressed by a moderate value of $t_{1}, L_{F P-G}$ and $t_{F P-G}$. Therefore, we can fix these three parameters to adjust the electric field peak at the gate edge, close to but not higher than $3 \mathrm{M} / \mathrm{cm}$. At the same time, less changes in the previous structure and little influence of FP thickness in enhancing $\mathrm{V}_{\mathrm{BD}}$, $\mathrm{t}_{\mathrm{FP}-\mathrm{S}}$ and $\mathrm{L}_{\mathrm{FP}-\mathrm{D}}$ can be confirmed too. Thus, we can confirm five parameter values firstly, as shown in Table 1 Then we can focus on the other two parameters, $t_{2}$ and LFP-s.

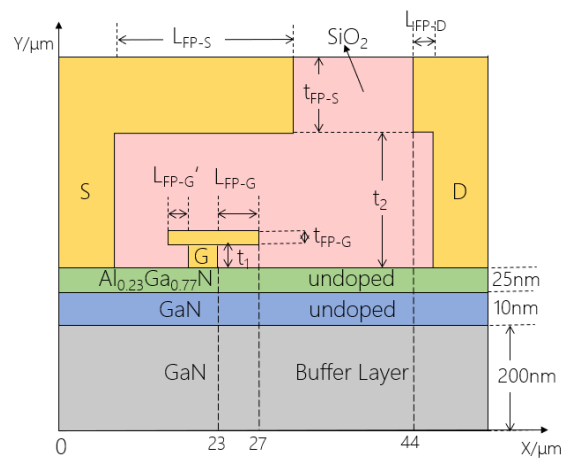

Figure 8. Device structure contained with FP-G, FP-S, and FP-D.

As shown in Figure 9, for different $L_{F P-S}$ which vary from $18 \mu \mathrm{m}$ to $28 \mu \mathrm{m}$, the moderated value (up to the highest $\mathrm{V}_{\mathrm{BD}}$ ) of $\mathrm{t}_{2}$ is different. We can find the reason in Figure 10a. Only when three peaks are uniform and close to $3 \mathrm{MV} / \mathrm{cm}$, could we achieve the highest $\mathrm{V}_{\mathrm{BD}}$. Meanwhile, comparing Figure 11a with Figure 11b, the potential lines distribution of the former are more crowded than that of the latter, resulting in a lower $\mathrm{V}_{\mathrm{BD}}$ [14].

However, no matter what the value of $t_{2}$ is, there is the highest $V_{B D}$ of all lengths for a FP-S of $24 \mu \mathrm{m}$. When $\mathrm{L}_{\mathrm{FP}-\mathrm{S}}$ is between $24 \mu \mathrm{m}$ to $26 \mu \mathrm{m}$, combined with the optimal $\mathrm{t}_{2}=1.7 \mu \mathrm{m}$, we can acquire the highest $\mathrm{V}_{\mathrm{BD}}$ of $2200 \mathrm{~V}$. Then, when $\mathrm{L}_{\mathrm{FP}-\mathrm{S}}$ is $28 \mu \mathrm{m}$, due to the narrow distance between FP-S and FP-D, the electric field peak of the FP-S edge will become higher, which makes $\mathrm{V}_{\mathrm{BD}}$ decrease. Figure 10b shows the electric field distributions for different $t_{2}$ along the channel in HEMT when LFP-S is fixed to $24 \mu \mathrm{m}$. When $t_{2}=1950 \mathrm{~nm}$, the two electric field peaks of FP-G edge and FP-S edge are approximate but not high enough to cause breakdown. So, when $V_{\mathrm{BD}}$ is around $2200 \mathrm{~V}$, the highest electric field peak appears at the gate edge. Hence, the crucial way to enhance breakdown voltage is to 
adjust relative FP parameters. By means of $t_{2}$ and $L_{F P-S}$, the two electric field peaks at each FPs edge could be uniformed to be closely equal but less than $3 \mathrm{M} / \mathrm{cm}$; and if the highest electric field peak appears at the gate edge, we would acquire the highest $\mathrm{V}_{\mathrm{BD}}$.

Table 1. Optimized parameter values.

\begin{tabular}{cc}
\hline Parameter & Optimized Value \\
\hline $\mathrm{t}_{1}$ & $250 \mathrm{~nm}$ \\
$\mathrm{~L}_{\mathrm{FP}-\mathrm{G}}$ & $4 \mu \mathrm{m}$ \\
$\mathrm{t}_{\mathrm{FP}-\mathrm{G}}$ & $100 \mathrm{~nm}$ \\
$\mathrm{t}_{\mathrm{FP}-\mathrm{S}}$ & $1.4 \mu \mathrm{m}$ \\
$\mathrm{L}_{\mathrm{FP}-\mathrm{D}}$ & $1 \mu \mathrm{m}$ \\
\hline
\end{tabular}

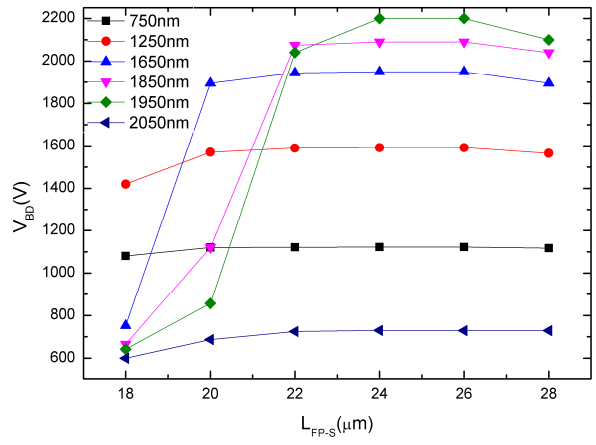

Figure 9. $\mathrm{V}_{\mathrm{BD}}$ as a function of $\mathrm{t}_{2}$ and $\mathrm{L}_{\mathrm{FP}-\mathrm{S}}$.

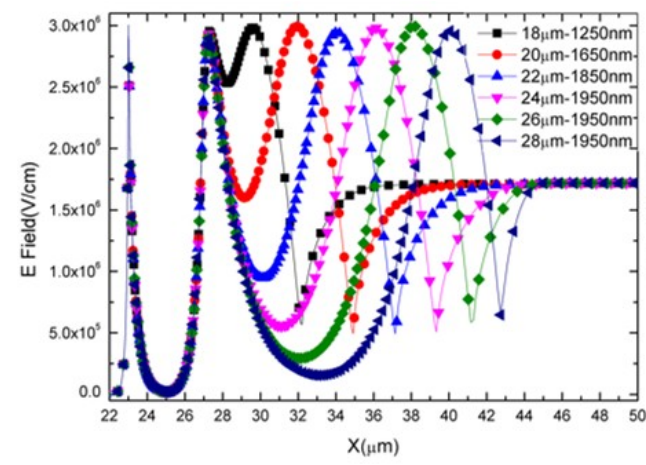

(a)

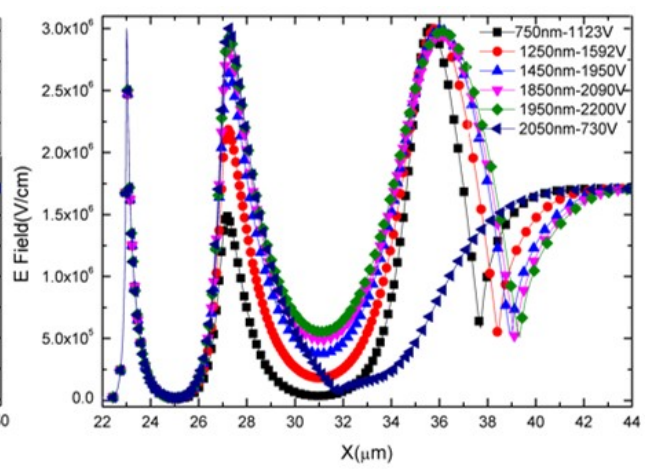

(b)

Figure 10. (a) The electric field distributions along the channel in HEMT with different $L_{F P-S}$ under highest $\mathrm{V}_{\mathrm{BD}}$; (b) the electric field distributions along the channel in HEMT when $\mathrm{L}_{\mathrm{FP}-\mathrm{S}}=24$.

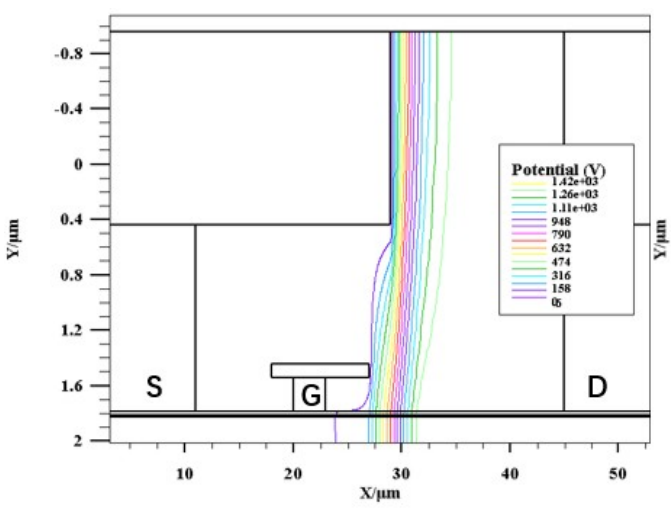

(a)

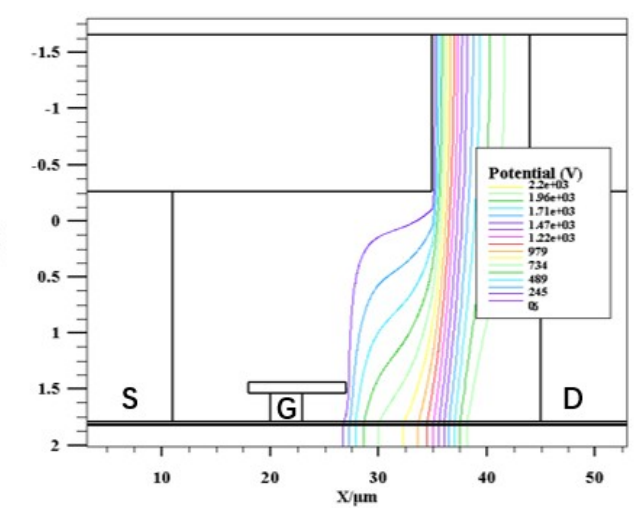

(b)

Figure 11. The Potential distributions in HEMT. (a) $\mathrm{L}_{\mathrm{FP}-\mathrm{S}}=18 \mu \mathrm{m}$ with $\mathrm{t}_{2}=1250 \mathrm{~nm}$ at $\mathrm{V}_{\mathrm{BD}}=1420 \mathrm{~V}$; (b) $\mathrm{L}_{\mathrm{FP}-\mathrm{S}}=24 \mu \mathrm{m}$ with $\mathrm{t}_{2}=1950 \mathrm{~nm}$ at $\mathrm{V}_{\mathrm{BD}}=2200 \mathrm{~V}$. 


\section{Conclusions}

In this paper, the effect of geometrical variables of FP and insulator layer on field distribution and $\mathrm{V}_{\mathrm{BD}}$ were investigated systematically. An AlGaN/GaN HEMT with FP-G, FP-S and FP-D simultaneously was also studied. On account of the incorporation of three FPs, the structure becomes more complex, and more parameters are needed for it to be optimized. Therefore, systematic simulation of these parameters could provide a correct direction for the design of a practical device. By Silvaco TCAD, we optimize the length of FPs, thickness of FPs, and the insulator layer, and acquire the highest $\mathrm{V}_{\mathrm{BD}}=2200 \mathrm{~V}$. The mechanism of $\mathrm{V}_{\mathrm{BD}}$ enhancement by inducing FPs is the effective modulation of potential lines distribution in the channel. By studying the potential lines and electric field distribution along the $\mathrm{AlGaN} / \mathrm{GaN}$ heterojunction interface, we can draw some conclusions. In terms of kinds of FP, FP-G can modulate potential lines distribution more uniformly and suppress the electric field peak at FP edge more effectively, compared with FP-S and FP-D. In terms of multiple field-plate combinations, the crucial way to enhance breakdown voltage is to adjust the relative FP parameters. Consequently, the electric field peaks at gate edge, FP-G edge and FP-S edge are uniform to be closely equal but lower than $3 \mathrm{M} / \mathrm{cm}$. Particularly, $\mathrm{L}_{\mathrm{FP}-\mathrm{S}}$ and $\mathrm{t}_{2}$ play the most important roles in modulating electric field peaks at FP-G and FP-S edge. Furthermore, the field-plate thickness should be taken into account for the inducing field-plate, in which the breakdown voltage increases with the increase of the field-plate thickness.

Author Contributions: Conceptualization, B.L. and Q.Z.; methodology, B.L. and J.Q.; validation, Q.Z.; formal analysis, B.L. and Q.Z.; writing—original draft preparation, B.L. and Q.Z.; writing—review and editing, H.W.; supervision, H.W.

Funding: This work was supported by Science and Technologies plan Projects of Guangdong Province (Nos. 2017B010112003, 2017A050506013), and by Applied Technologies Research and Development Projects of Guangdong Province (Nos. 2015B010127013, 2016B010123004), and by Science and Technologies plan Projects of Guangzhou City (Nos. 201504291502518, 201604046021, 201704030139, 201905010001), and by Science and Technology Development Special Fund Projects of Zhongshan City (Nos. 2017F2FC0002, 2017A1009).

Conflicts of Interest: The authors declare no conflict of interest. The funders had no role in the design of the study.

\section{References}

1. Mishra, U.K.; Shen, L.; Kazior, T.E.; Wu, Y.F. GaN-Based RF Power Devices and Amplifiers. Proc. IEEE 2008, 96, 287-305. [CrossRef]

2. Liu, Y.; Chai, C.; Chunlei, S.; Fan, Q.; Liu, Y. Optimization design on breakdown voltage of AlGaN/GaN high-electron mobility transistor. J. Semicond. 2016, 37, 40-44. [CrossRef]

3. Zeng, F.; An, J.X.; Zhou, G.; Li, W.; Wang, H.; Duan, T.; Jiang, L.; Yu, H. A Comprehensive Review of Recent Progress on GaN High Electron Mobility Transistors: Devices, Fabrication and Reliability. Electronics 2018, 7, 377. [CrossRef]

4. Kuzuhara, M.; Asubar, J.T.; Tokuda, H. AlGaN/GaN high-electron-mobility transistor technology for high-voltage and low-on-resistance operation. Jpn. J. Appl. Phys. 2016, 55, 070101. [CrossRef]

5. Karmalkar, S.; Mishra, U.K. Enhancement of breakdown voltage in AlGaN/GaN high electron mobility transistors using a field plate. IEEE Trans. Electron Devices 2001, 48, 1515-1521. [CrossRef]

6. Zhang, N.Q.; Keller, S.; Parish, G.; Heikman, S.; Denbaars, S.; Mishra, U.K. High. breakdown GaN HEMT with overlapping gate structure. IEEE Electron Device Lett. 2000, 21, 421-423. [CrossRef]

7. Bahat-Treidel, E.; Hilt, O.; Brunner, F.; Sidorov, V.; Würfl, J.; Tränkle, G. AlGaN/GaN/AlGaN DH-HEMTs Breakdown Voltage Enhancement Using Multiple Grating Field Plates (MGFPs). IEEE Trans. Electron Devices 2010, 57, 1208-1216. [CrossRef]

8. Bahat-Treidel, E.; Sidorov, V.; Würfl, J.; Tränkle, G. Simulation of AlGaN/GaN HEMTs' Breakdown Voltage Enhancement Using Grating Field Plates. Simul. Semicond. Process. Devices 2007, 277-280. [CrossRef]

9. Dora, Y.; Chakraborty, A.; McCarthy, L.; Keller, S.; Denbaars, S.P.; Mishra, U.K. High Breakdown Voltage Achieved on AlGaN/GaN HEMTs With Integrated Slant Field Plates. IEEE Electron Device Lett. 2006, 27, 713-715. [CrossRef] 
10. Kong, X.; Wei, K.; Liu, G.-G.; Liu, X.-Y. Improvement of breakdown characteristics of an AlGaN/GaN HEMT with a U-type gate foot for millimeter-wave power application. Chin. Phys. B 2012, 21, 128501. [CrossRef]

11. Mao, W.; She, W.-B.; Yang, C.; Zhang, C.; Zhang, J.-C.; Ma, X.-H.; Zhang, J.-F.; Liu, H.-X.; Yang, L.-A.; Zhang, K.; et al. A two-dimensional fully analytical model with polarization effect for off-state channel potential and electric field distributions of GaN-based field-plated high electron mobility transistor. Chin. Phys. B 2014, 23, 87305. [CrossRef]

12. Kaddeche, M.; Telia, A.; Soltani, A. Modeling of AlGaN/GaN HEMTs using field-plate technology. In Proceedings of the 2009 3rd International Conference on Signals, Circuits and Systems (SCS), Medenine, Tunisia, 6-8 November 2009; pp. 1-4.

13. Wu, W.-H.; Lin, Y.-C.; Chin, P.-C.; Hsu, C.-C.; Lee, J.-H.; Liu, S.-C.; Maa, J.S.; Iwai, H.; Chang, E.Y.; Hsu, H.T. Reliability improvement in GaN HEMT power device using a field plate approach. Solid-State Electron. 2017, 133, 64-69. [CrossRef]

14. Mao, W.; Fan, S.-J.; Du, M.; Zhang, J.-F.; Zhang, J.-C.; Zheng, X.-F.; Wang, C.; Ma, X.-H.; Zhang, J.-C.; Hao, Y. Analysis of the modulation mechanisms of the electric field and breakdown performance in AlGaN/GaN HEMT with a T-shaped field-plate. Chin. Phys. B 2016, 25, 127305. [CrossRef]

15. Amit, M.; Rawal, D.S.; Sharma, S.; Kapoor, S.; Liashram, R.; Chaubey, R.K.; Vinayak, S.; Sharma, R.K. Design and Fabrication of Multi-finger Field Plate for Enhancement of AlGaN/GaN HEMT Breakdown Voltage. Defence Sci. J. 2018, 68, 290. [CrossRef]

16. Saito, W.; Nitta, T.; Kakiuchi, Y.; Saito, Y.; Tsuda, K.; Omura, I.; Yamaguchi, M. Suppression of Dynamic On-Resistance Increase and Gate Charge Measurements in High-Voltage GaN-HEMTs With Optimized Field-Plate Structure. IEEE Trans. Electron Devices 2007, 54, 1825-1830. [CrossRef]

17. Benny Sathish, M.; Fletcher, A.S.A. Design and modeling of HEMT using field plate technique. In Proceedings of the 2017 International Conference on Innovations in Electrical, Electronics, Instrumentation and Media Technology (ICEEIMT), Coimbatore, India, 3-4 February 2017; pp. 157-159. [CrossRef]

18. Uemoto, Y.; Shibata, D.; Yanagihara, M.; Ishida, H.; Matsuo, H.; Nagai, S.; Batta, N.; Li, M.; Ueda, T.; Tanaka, T; et al. $8300 \mathrm{~V}$ Blocking Voltage AlGaN/GaN Power HFET with Thick Poly-AlN Passivation. In Proceedings of the 2007 IEEE International Electron. Devices Meeting, Washington, DC, USA, 10-12 December 2007; pp. 861-864.

19. Kabemura, T.; Ueda, S.; Kawada, Y.; Horio, K. Enhancement of Breakdown Voltage in AlGaN/GaN HEMTs: Field Plate Plus High- $k$ Passivation Layer and High Acceptor Density in Buffer Layer. IEEE Trans. Electron Devices 2018, 65, 3848-3854. [CrossRef]

20. Aamir Ahsan, S.; Ghosh, S.; Sharma, K.; Dasgupta, A.; Khandelwal, S.; Chauhan, Y.S. Capacitance Modeling in Dual Field-Plate Power GaN HEMT for Accurate Switching Behavior. IEEE Trans. Electron Devices 2016, 63, 565-572. [CrossRef]

21. Saito, W.; Kuraguchi, M.; Takada, Y.; Tsuda, K.; Omura, I.; Ogura, T. Design Optimization of High Breakdown Voltage AlGaN-GaN Power HEMT on an Insulating Substrate for $R_{O N} A-V_{B}$ Tradeoff Characteristics. IEEE Trans. Electron Devices 2005, 52, 106-111. [CrossRef]

22. Mao, W.; She, W.-B.; Yang, C.; Zhang, J.-F.; Zheng, X.-F.; Wang, C.; Hao, Y. Reverse blocking characteristics and mechanisms in Schottky-drain AlGaN/GaN HEMT with a drain field plate and floating field plates. Chin. Phys. B 2016, 25, 017303. [CrossRef]

23. Lian, Y.-W.; Lin, Y.-S.; Lu, H.-C.; Huang, Y.-C.; Hsu, S.S.H. AlGaN/GaN HEMTs on Silicon With Hybrid Schottky-Ohmic Drain for High Breakdown Voltage and Low Leakage Current. IEEE Electron Device Lett. 2012, 33, 973-975. [CrossRef]

24. Silvaco TCAD. Version 2016 Software for DC, AC and Transient Analysis for Compound Semiconductor Devices; Silvaco Inc.: Santa Clara, CA, USA, 2016.

25. Hu, J.; Stoffels, S.; Lenci, S.; Bakeroot, B.; De Jaeger, B.; Van Hove, M.; Ronchi, N.; Venegas, R.; Liang, H.; Zhao, M.; et al. Performance Optimization of Au-Free Lateral AlGaN/GaN Schottky Barrier Diode with Gated Edge Termination on 200-mm Silicon Substrate. IEEE Trans. Electron Devices 2016, 63, 997-1004. [CrossRef]

26. Zhe, C.; Yun, Z.; Lian, Z.; Zhao, Y.B.; Wang, J.X.; Li, J.M. Normally-off recessed MOS-gate AlGaN/GaN HEMTs with over $+4 \mathrm{~V}$ saturation drain current density and a $400 \mathrm{~V}$ breakdown voltage. In Proceedings of the China International Forum on Solid State Lighting: International Forum on Wide Bandgap Semiconductors, Beijing, China, 15-17 November 2016. 
27. Hu, J.; Lenci, S.; Stoffels, S.; Jaeger, B.D.; Groeseneken, G.; Decoutere, S. Leakage-current reduction and improved on-state performance of Au-free AlGaN/GaN-on-Si Schottky diode by embedding the edge terminations in the anode region. Phys. Status Solidi C 2014, 11, 862-865. [CrossRef]

28. Hanawa, H.; Onodera, H.; Nakajima, A.; Horio, K. Numerical Analysis of Breakdown Voltage Enhancement in AlGaN/GaN HEMTs With a High-k Passivation Layer. IEEE Trans. Electron Devices 2014, 61, 769-775. [CrossRef]

29. Chvála, A.; Nagy, L.; Marek, J.; Priesol, J.; Donoval, D.; Blaho, M.; Gregušová, D.; Kuzmík, J.; Šatka, A. Characterization of Monolithic InAIN/GaN NAND Logic Cell Supported by Circuit and Device Simulations. IEEE Trans. Electron Devices 2018, 65, 2666-2669. [CrossRef]

30. Horio, K.; Yonemoto, K.; Takayanagi, H.; Nakano, H. Physics-based simulation of buffer-trapping effects on slow current transients and current collapse in GaN field effect transistors. J. Appl. Phys. 2005, 98, 124502. [CrossRef]

31. Hanawa, H.; Horio, K. Increase in breakdown voltage of AlGaN/GaN HEMTs with a high-kdielectric layer. Phys. Status Solidi A 2014, 211, 784-787. [CrossRef]

32. Shealy, J.R.; Prunty, T.R.; Chumbes, E.M.; Ridley, B.K. Growth and passivation of AlGaN/GaN heterostructures. J. Cryst. Growth 2003, 250, 7-13. [CrossRef]

33. Xu, Z.; Zhou, Y.; Li, J. $200{ }^{\circ} \mathrm{C}$ normally off AlGaN/GaN MISFET with $321 \mathrm{~mA} / \mathrm{mm}$ drain current density and $1055 \mathrm{~V}$ breakdown voltage. Electron. Lett. 2019, 55, 282-283. [CrossRef]

34. Aminbeidokhti, A.; Dimitrijev, S.; Han, J.; Chen, X.; Xu, X. The Power Law of Phonon-Limited Electron Mobility in the 2-D Electron Gas of AlGaN/GaN Heterostructure. IEEE Trans. Electron Devices 2016, 63, 2214-2218. [CrossRef]

35. Kunihiro, K.; Kasahara, K.; Takahashi, Y.; Ohno, Y. Experimental evaluation of impact ionization coefficients in GaN. IEEE Electron Device Lett. 1999, 20, 608-610. [CrossRef]

(C) 2019 by the authors. Licensee MDPI, Basel, Switzerland. This article is an open access article distributed under the terms and conditions of the Creative Commons Attribution (CC BY) license (http:/ / creativecommons.org/licenses/by/4.0/). 